\title{
Thymic Neuroendocrine Neoplasms: Biological Behaviour and Therapy
}

\author{
Ru Jia ${ }^{a}$ Petra Sulentic $^{b}$ Jian-Ming Xua Ashley B. Grossman ${ }^{c}$ \\ a Department of Gastrointestinal Oncology, Affiliated Hospital Cancer Center, Academy of Military Medical Sciences, \\ Beijing, China; ${ }^{b}$ Department of Clinical Pharmacology, University of Cambridge, Cambridge, and ${ }^{\mathrm{C} D e p a r t m e n t}$ of \\ Endocrinology, Oxford Centre for Diabetes, Endocrinology and Metabolism, University of Oxford, Oxford, UK
}

\section{Keywords}

Thymus · Carcinoid · Neuroendocrine tumour . Ectopic ACTH · Multiple endocrine neoplasia-1 . Bronchopulmonary carcinoids

\begin{abstract}
Thymic neuroendocrine neoplasms are rare tumours, but their management can often be highly problematic. While previously assumed to be essentially variants of bronchopulmonary (lung) carcinoids, they are generally more aggressive and more difficult to treat. Some $25 \%$ are associated with multiple endocrine neoplasia-1, while a higher proportion are associated with the ectopic ACTH syndrome, and occasionally both. We discuss the classification of these tumours, their biology as far as is known, and their clinical, biochemical and imaging features. We also review possible management options and suggest stratagems to optimise their treatment, which even today is far from optimal.
\end{abstract}

๑) 2017 S. Karger AG, Basel

\section{Introduction}

Thymic neuroendocrine neoplasms (NEN) are rare tumours. In the most recent SEER database, the incidence of thymic NENs was $0.02 / 100,000$ population per year [1] among Caucasian and $0.04 / 100,000$ population per year

\section{KARGER}

(C) 2017 S. Karger AG, Basel

E-Mail karger@karger.com

www.karger.com/nen among Asian/Pacific islanders, which is far less than the incidence of broncho-pulmonary (lung) carcinoids. Overall, they account for $2 \%$ of all mediastinal tumours and $5 \%$ of all thymic tumours [2]. Since the histological appearance of thymic NENs is in some respects similar to that of lung carcinoids, for a long period of time they have been considered as a single group of tumours in terms of classification and grading, and especially in terms of their treatment modalities. However, more recently, it has been realised that in terms of their behaviour and genetic background, they are an uncommon but quite distinct group of neoplasms, separate from both other thymic tumours as well as broncho-pulmonary carcinoids.

Thymic carcinoids were first described as a distinct entity by Rosai and Higa in 1972 [3]. Shortly thereafter, various reports revealed several distinctive features of thymic NENs compared with NENs in other sites, particularly: (1) their low incidence; (2) they usually occurred at a relatively advanced stage; (3) they tended to be highly aggressive with a poor prognosis; (4) they were not infrequently associated with multiple endocrine neoplasia-1 (MEN-1); and (5) there may be ethnic differences in prevalence, particularly between Caucasians and Asians. This article reviews the current relatively sparse published literature reports together with our own clinical experience from both Europe and Asia in order to summarise the current status of thymic NENs, to indicate current treatment modalities, and to point out future areas where research is needed.

Prof. Ashley B. Grossman

Oxford Centre for Diabetes, Endocrinology and Metabolism

Churchill Hospital

Oxford OX3 7LE (UK)

E-Mail ashley.grossman@ocdem.ox.ac.uk 
Table 1. 2015 WHO classification for bronchopulmonary NENs and thymic NENs

\begin{tabular}{lllll}
\hline Histological type & Grade & Mitoses $/ 2 \mathrm{~mm}^{2}$ & Necrosis & Differentiation \\
\hline Typical carcinoids & Low & $<2$ & And absence of necrosis & Well \\
Atypical carcinoids & Intermediate & $2-10$ & And/or foci of necrosis & Well \\
Large cell carcinoma & High & $>10$ & And geographic necrosis & Poorly \\
Small cell carcinoma & & & & \\
\hline
\end{tabular}

WHO, World Health Organization; NENs, neuroendocrine neoplasms.

\section{Pathology and Staging}

\section{Histological Classification}

The existence of a three-tier pathological classification of low-grade, intermediate-grade and high-grade neuroendocrine tumours (NET) was initially proposed by Rosai and Higa in 1972. According to the 2015 World Health Organization (WHO) [4], broncho-pulmonary and thymic NENs are classified into 4 categories: typical carcinoids (TC), atypical carcinoids (AC), large cell neuroendocrine carcinomas (LCNEC), and small cell (thymic) carcinomas (SCLC) (Table 1). TC are low-grade and AC as intermediate-grade are well differentiated and are to be referred to as "thymic carcinoids," while LCNEC and SCLC arehigh-grade and poorly differentiated (HGNEC). TC account for $18-36 \%$, AC for $40-55 \%$, and poorly differentiated tumours account for $19-28 \%$ of all thymic NENs [5-7]. In the 2014 report by Strobel et al. [5], the 5 -year survival rates for thymic TC (TTC), thymic AC (TAC), and HGNEC were 100,60 , and $30 \%$, respectively, with 10-year survival rates for TTC and TAC of 50 and $30 \%$. However, it is still unclear as to whether this classification is an independent prognostic factor $[1,7]$.

Although the current classification system is based on the classification of lung carcinoids, the current evidence suggests that thymic NENs behave in a more aggressive manner compared to lung carcinoids. The WHO classification is based on mitotic count and the presence of necrosis: the cut-off value for TC and AC in terms of mitotic count is 2 per $2 \mathrm{~mm}^{2}$, which might not be an accurate measure when using only a small amount of tissue, especially in biopsy samples. Some studies have suggested that the current grading system does not highly correlate with survival, while adding a Ki-67 assessment did show statistical significance in terms of survival $[8,9]$. In the series reported by Ahn et al. [10], 3 of the patients showed mitotic counts of more than 10 per 10 high-power fields but did not show a lack of differentiation: the clinical behaviour of the tumours in these patients supported a diagno- sis of AC (Fig. 1). This is similar to the situation for gastroentero-pancreatic NENs where discrepancies occur in terms of mitoses/Ki-67 and degree of differentiation, and recent data have suggested that the differentiation status is crucial [11]. It is clear that more data are needed in order to establish the diagnostic features of, and the reasons for, the more aggressive course of thymic carcinoids compared to lung carcinoids. However, this may prove difficult owing to the rarity of thymic carcinoids, and multicentre international collaboration will be necessary.

\section{Staging}

While there is no specific and well-recognised staging system for thymic NENs due to their rarity [12], the system devised by Masaoka and Masaoka-Koga (MK) [13] for thymoma is recommended worldwide, especially for resectable tumours. In addition, a simplified staging system has been proposed by Suster and Moran [14] in which stage I lesions are encapsulated, stage II tumours are locally invasive, and stage III tumours are those which present with lymph node or visceral metastasis. In the SEER database, all carcinoids were divided into localised, regional, and distant [1]. For thymomas, the International Thymic Malignancies Interest Group (ITMIG) and the International Association for the Study of Lung Cancer (IASLC) have summarised a large group of thymic tumours and applied the 8th AJCC TNM staging system for thymomas and thymic carcinomas [15]. Interestingly, in 2016 a Chinese study failed to identify any differences in either disease-free survival or overall survival by using either MK or the new TNM staging systems in thymic well-differentiated carcinoma [16].

However, in all these staging systems, lymph node metastases have proven to be problematic and have been differentially treated; in the Masaoka-based or Moran systems, lymph node metastases were considered as stage IV, while in the SEER database they were considered as only regional. Furthermore, in all these systems tumour size was not a feature used for classification. As is well established,
106

Neuroendocrinology 2017;105:105-114 DOI: $10.1159 / 000472255$
Jia/Sulentic/Xu/Grossman 


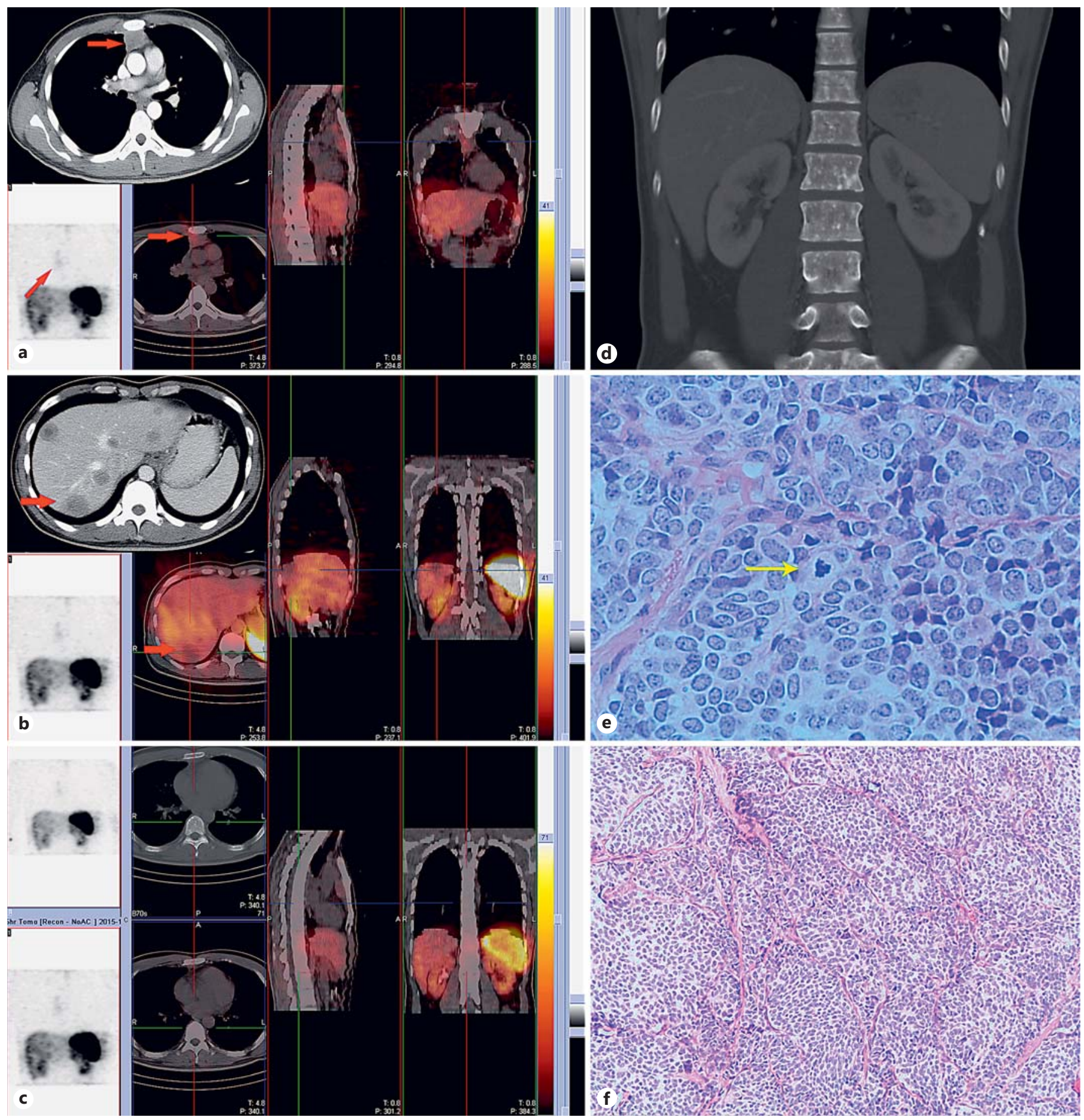

Fig. 1. This male patient was treated at the Affiliated Hospital Cancer Center, Academy of Military Medical Sciences, Beijing, and developed a thymic carcinoid (a) with liver (b) and bone (c, d) metastases. His SRS was slightly positive in the thymus and nega- tive at the metastatic sites. The histopathology showed a mitotic count of 15 per $2 \mathrm{~mm}^{2}$ (one shown with arrow; e), but it was well differentiated (f). e Haematoxylin-eosin, original magnification $\times 40$. $\mathbf{f}$ Hematoxylin-eosin, original magnification $\times 10$. 
Table 2. Differences between lung NETs and thymic NETs

\begin{tabular}{lll}
\hline Features & $\begin{array}{l}\text { Lung } \\
\text { NETs }\end{array}$ & $\begin{array}{l}\text { Thymic } \\
\text { NETs }\end{array}$ \\
\hline $\begin{array}{l}\text { Incidence (per 100,000 per year) } \\
\text { Median tumor size, cm }\end{array}$ & $0.2-2$ & 0.2 \\
Grading, \% & 3 & 8 \\
$\quad$ TC & $66-90$ & $18-36$ \\
$\quad$ AC & $10-34$ & $40-55$ \\
Sex ratio & $1: 1$ & $2-3: 1$ \\
MEN-1 related, \% & $5-10$ & 25 \\
Symptoms, \% & 2 & \\
$\quad$ Carcinoid syndrome & 2 & $40-50$ \\
$\quad$ Cushing syndrome & & \\
TC, \% & $87-100$ & $50-100$ \\
$\quad$ 5-year survival rate & $82-92$ & $9-78$ \\
10-year survival rate & & \\
AC, \% & $30-90$ & $20-80$ \\
5-year survival rate & $35-67$ & $0-55$ \\
$\quad$ 10-year survival rate & &
\end{tabular}

NETs, neuroendocrine tumors; TC, typical carcinoids; AC, atypical carcinoids; MEN-1, multiple endocrine neoplasia-1.

thymic NENs may grow to a very large size, and several studies had drawn the conclusion that tumour size (with a 5 - to 7 -cm cut-off) is a significant prognostic factor $[1,9]$.

In relation to bronchopulmonary carcinoids, some have suggested that lymph node invasion has a significant influence on the prognosis of $\mathrm{AC}$, while $\mathrm{TC}$ patients with metastases or a significant recurrence may still show longterm survival [17]. While no statistically significant difference was found in 5-year and 10-year survival between lung and thymic carcinoids $[5,6,9,17]$ (Table 2), in the study by Yao et al. [18] the overall survival for lung carcinoids was significantly longer than thymus both in localised and regional patients, suggesting a clear difference in the biological behaviour of lung and thymic NETs [19]. Moreover, the 5 -year survival rate in several large studies of thymic NENs varied from 50 to $100 \%$ in well-differentiated patients and from 20 to $80 \%$ in moderate-differentiated patients [1, 5-7]. It seems likely that the wide range in survival is due to the varying staging assessments and different proportions of radical resection performed in these series, confirming the diversity in thymic NENs. The staging system appears to have been useful in considering initial treatment options, but seems not to reflect the degree of malignancy and the overall survival. We would suggest that any staging system should be combined with a careful histological classification including assessment of Ki-67 and degree of differentiation in order to determine accurate outcomes.

108

Neuroendocrinology 2017;105:105-114 DOI: $10.1159 / 000472255$

\section{Clinical Manifestations}

On the basis of the SEER database analysis and the largest series reported in 2015, the median age at thymic NEN diagnosis was 54-59 years [7, 18]. However, the peak incidence was in the 2 nd to 4 th decades [20]. The incidence is 3 times higher for men than for women [21]. Approximately one-third of patients are asymptomatic and are identified on routine imaging examination. Some tumours may grow large enough to compress nerve or vessels, and patients present with a superior vena cava syndrome or local pain.

One-third to half of cases are functionally active. Such patients may present with other evidence of MEN-1 or the ectopic ACTH syndrome (EAS). Unlike other types of NENs, in patients with thymic carcinoids a carcinoid syndrome is only very rarely seen (less than 1\%), whereas ectopic Cushing syndrome (CS) occurs in up to $50 \%$ of all cases [21-23], although this may be an overestimate.

The median size of thymic NENs on presentation was reported to be $8 \mathrm{~cm}$ [7]. The sites of metastases differ from other carcinoids: bone metastases were reported as present in $33 \%$ and liver metastases in only $3 \%$ of these patients [6, 24]; for bronchial NETs, liver and bone were both the most common sites of metastases [25].

\section{Thymic Carcinoids Related to MEN-1}

Approximately $25 \%$ of thymic carcinoids are associated with MEN-1, while some $2-8 \%$ of patients with MEN-1 develop thymic carcinoids [26, 27]. Due to its low incidence, there have previously only been very small series of case reports of thymic carcinoids in MEN-1. Thymic NENs have been reported to be one of the major causes of death in MEN-1 patients [24, 28]. Recent studies showed that MEN-1 patients who developed thymic carcinoids showed increased mortality [29], different to that seen with broncho-pulmonary carcinoids [30]. It would thus seem prudent for patients with MEN-1 to undergo reasonably frequent radiological screening with thoracic CT scanning with contrast, and simple plain chest radiology may not be adequate [31]. However, the actual frequency of such scanning must be a compromise between discovering such a low-incidence carcinoid and the dangers of therapeutic diagnostic radiation.

\section{Differences between Asians and Caucasians}

In most reports from the US and Europe, thymic carcinoids associated with the MEN-1 syndrome have almost exclusively occurred in male and cigarette smokers [18, 26], while broncho-pulmonary carcinoids were female 
predominant. However, a Japanese series showed that $36 \%$ of MEN-1 patients with thymic carcinoids were female: of the 10 patients only one was a smoker. In addition, there are several case reports from Asia on female MEN-1 patients with thymic carcinoids $[32,33]$. However, in a series from the MD Anderson hospital in Houston in 2016, there was a similar male/female ratio of 2:1 in both ethnic groups, suggesting that ethnic differences might not be significant [34]. It would appear to be reasonable for all patients with MEN-1 to undergo surveillance screening for a thymic carcinoid, even female non-smokers [35].

The percentage of TC might be less in Asians compared with Caucasians. In a Korean report, no TC were found in 21 patients [10]. Another Chinese study reported 3 out of 22 patients were TC (13.6\%), and in our own data from the Affiliated Hospital Cancer Center, Academy of Military Medical Sciences, Beijing, a series of 15 patients showed TC in $13 \%$, AC in $60 \%$, while $27 \%$ were poorly differentiated, which is in accordance with the reports above showing a predominance of $\mathrm{AC}$ in Asian patients. In the report from the SEER database in which white patients made up $83 \%$ of 160 patients, the percentage of TC was $58 \%$. However, this distinction of more TC in Caucasian patients and predominant AC in Asian patients is contradicted in another large series where TC only accounted for $28 \%$ of 169 patients of which $36 \%$ were Asian [7]. Furthermore, the WHO 2014 classification also claims a larger percentage of AC in Caucasian patients than previously recognised, so currently the situation remains unresolved.

\section{Thymic Carcinoids with CS}

The EAS is responsible for some $15 \%$ of patients with ACTH-dependent CS. Carcinoids originating in the neck and thorax are the most frequent cause of EAS, accounting for half to two-thirds of all EAS cases. Of patients with EAS, thymic carcinoids in turn account for $5-42 \%$ of cases $[36,37]$. Up to $50 \%$ of sporadic thymic carcinoids show ectopic ACTH secretion. Nevertheless, EAS due to thymic carcinoids remains a rare disorder. Thymic carcinoids with CS show a worse outcome than those without CS [38], but it is unclear as to whether they are inherently more aggressive or that it is the metabolic complication of the CS which is responsible. The EAS may also be highly periodic, as reported in one Japanese patient [39].

Thymic carcinoids associated with EAS usually showed an age of presentation of 21-35 years, although one series showed that 4 out of 12 patients were children [38, 40]. The sex ratio was 1:1. Hyperpigmentation was a prominent feature in the series from the NIH [38], but was not mentioned in the report by Chen et al. [40]. Overexpres-

Thymic Carcinoids sion of p21 activated kinase 3 (PAK3) has been detected in thymic carcinoids causing EAS [41].

Some early studies suggested the MEN-1-related thymic carcinoids are not associated with the EAS, in contrast to sporadic cases. However, there are numerous case reports showing that MEN-1 patients with thymic carcinoids could also produce ectopic ACTH [18, 42-44]. Thus, while rare, the possibility of MEN-1 should be considered in all patients with thymic carcinoids. There is also a report of the ectopic co-secretion of ACTH and gastrin by a thymic carcinoid [45].

\section{Investigations}

\section{Nuclear Medicine}

The normal thymus possesses somatostatin receptors principally of the subtype SSTR2. Most studies have reported positive findings on somatostatin receptor scintigraphy (SRS) $[26,40]$. In the series reported by Chen et al. [40], 8 of 9 patients who underwent SRS showed a tumour location consistent with the SRS-CT scan. However, Gibril et al. [27] demonstrated that SRS was only positive in 4 out of $6 \mathrm{MEN}$ 1 patients, being less sensitive than CT scanning or MRI for both primary sites and bone metastases. In another study, the sensitivity of SRS ranged between 53 and 85\% [46].

Most SRS have been performed with ${ }^{111}$ In-octreotideSPECT, with little information on either ${ }^{68} \mathrm{Ga}$-DOTATOC/DOTATATE PET/CT or ${ }^{18} \mathrm{FDG}$ PET/CT in thymic NENs. As a relatively aggressive tumour, several case reports have demonstrated ${ }^{18} \mathrm{FDG}$ uptake in thymic NENs, an uncommon finding in most other NENs [47-49]. In the latest study which reviewed the reports of patients with thymic carcinoids associated with EAS, the sensitivity of conventional SRS, ${ }^{18} \mathrm{FDG}$-PET, and ${ }^{68} \mathrm{Ga}$-DOTATOC PET/CT in thymic carcinoids was $12 / 14,5 / 8$, and $2 / 4$, respectively, with positivity on CT scanning in $85 \%$ [50]. Both conventional SRS and ${ }^{68} \mathrm{Ga}$-DOTATOC PET/CT are helpful in surveillance of thymic NENs $[51,52]$, but ${ }^{68} \mathrm{Ga}$ DOTATOC PET/CT might be the best imaging modality to identify bone metastases in positive patients [53].

It will certainly be important in future series to correlate cross-sectional imaging with $\mathrm{CT}$ and/or MRI with other functional modalities, both in terms of diagnostic detection and possible therapy (see below), and to crosscorrelate this with histopathological classifications.

\section{Biochemical Investigations}

Thymic carcinoids should be evaluated with chromogranin A as for other NENs, while of limited value for de-

Neuroendocrinology 2017;105:105-114 DOI: $10.1159 / 000472255$ 
tection it can be a useful marker for follow-up and investigating responses to therapeutic manoeuvres. Investigation for the ectopic secretion of other hormones as in the EAS should be carried as for other NENs, when suspected.

Many NENs, especially of mid-gut origin, secrete serotonin, and this may be associated with the carcinoid syndrome and elevated urinary excretion of both serotonin and particularly its metabolite 5-hydroxyindoleacetic acid (5-HIAA). Urinary 5-HIAA has been widely used, although specific food intake has to be precisely monitored and restricted. However, urinary 5-HIAA is derived from serotonin, while foregut carcinoids, such as thymic and broncho-pulmonary carcinoids, often lack aromatic amino-acid decarboxylase which is necessary to convert tryptophan to serotonin and ultimately to urinary 5-HIAA. Thus, urinary serotonin or 5-HIAA measurement is not routinely recommended for the detection of carcinoids in the chest cavity.

\section{Gene Mutations}

The specific genotype in thymic NENs with or without MEN-1 has not been identified. MEN-1 mutations varied a lot in different families, and the loss of heterozygosity (LOH) at 11q13 in thymic NETs of the MEN-1 syndrome is much scarcer than in other MEN-1-related tumours [54]. In the report by Gibril et al. [27], no LOH at the $11 \mathrm{q} 13$ locus was found in thymic NENs in which 11q13 $\mathrm{LOH}$ was detected in pancreatic NETs in the same patient. This suggested that the molecular pathogenesis of thymic NENs in MEN-1 was different to other MEN1-related disease such as hyperparathyroidism, pituitary tumours, pancreatic NETs, and gastric NETs, all of which demonstrate 11q13 LOH. Modifier genes and promoter methylation may be involved [55]. Very recently, somatic mutations were sought using whole-exome sequencing in 9 thymic NENs associated with the EAS; while no recurrent mutated genes were reported, probably pathogenic mutations in HRAS, PAK1, and MEN1 were identified in individual tumours and thus may be involved in tumorigenesis [56].

Chromosomal imbalances increased from low grade to intermediate grade to high grade. In the sporadic thymic NENs, genetic alterations were found in most of the chromosomes in which 8q24 (MYC gene loss) was the most frequent alteration [5]. There were both overlapping and unique genetic alterations among carcinoids and high-grade NEC such that these 2 groups were hypothesised to be separate entities [5]. The pattern of chromosomal aberration of thymic carcinoids is significantly different from that of broncho-pulmonary carcinoids [4].

\section{Treatment}

The rarity of thymic NENs has resulted in a lack of prospective clinical trials and large series, such that there are few clear consensus statements or guidelines for optimal treatment. To date, the treatment of thymic NENs has generally followed that of broncho-pulmonary carcinoids, in spite of the fact that the SEER database suggested a clear difference in relation to localised, regional or distant G1/G2 disease [18]. Thus, while more aggressive treatment strategies have been used for thymic carcinoids, they are not based on any clear evidence.

\section{Surgery}

It is widely agreed that radical surgery is the only curative method for resected lesions, although more than half of the patients will be locally advanced or have metastases. Patients who underwent $\mathrm{R} 0$ resection had a longer overall survival than those whose tumour could not be completely removed [7]. Surgery should include peripheral lymph node dissection to achieve a radical resection. Palliative resection, operation after local recurrence or debulking in order to relieve compression symptoms may also be indicated. However, the recurrence rates have differed from 17.1 to $83 \%[5,7,9]$, confirming the pleiotropic and rather unpredictable nature of these tumours. Perioperative chemotherapy and/or radiation therapy can also be considered, especially for incompletely resected tumours which might be more aggressive.

Since thymic NENs are very rarely the first presenting feature of MEN-1 patients, and considering the high incidence of hyperparathyroidism in this condition, prophylactic transcervical thymectomy during total or subtotal parathyroidectomy has been recommended in some studies. Concomitant thymectomy has been performed to remove residual parathyroid gland and also reduce the risk of thymic NENs [18]. However, some reports showed thymectomy will not completely prevent the development of thymic NENs $[27,57,58]$, which may be explained as the transcervical route may leave the intrathoracic part of the thymus behind. Thus, regular screening for thymic NENs even after thymectomy in MEN-1 remains mandatory. Nevertheless, thymectomy should undoubtedly decrease the rate of developing thymic NENs without increased safety issues, and therefore this procedure is generally recommended as routine practice.

\section{Radiation Therapy}

The value of external beam radiotherapy for thymic NENs is still unclear, and most studies have reported no
110

Neuroendocrinology 2017;105:105-114 DOI: $10.1159 / 000472255$
Jia/Sulentic/Xu/Grossman 
marked effect on long-term survival. In adjuvant settings, Tiffet et al. [59] reported a better outcome in patients receiving adjuvant radiation therapy, while other series failed to show any benefit for such treatment $[7,9]$. Nevertheless, in most series, postoperative radiotherapy \pm chemotherapy were still performed $[7,10,34,60]$, although none of the current guidelines recommend adjuvant therapy for carcinoids. In broncho-pulmonary carcinoids, recurrence is uncommon and was sometimes detected 10-30 years after surgery [61], while in thymic carcinoids the recurrence rate could reach as high as $83 \%$. Filosso et al. [7] noted that recurrence mainly occurred within 8 years after surgery. However, in spite of clear evidence in its favour, localised radiotherapy is often employed for residual disease following incomplete surgery.

In one patient with an unresectable tumour, proton beam therapy was used and caused tumour shrinkage over 2 years [62]; the role of such therapy and focused radiotherapy remains unclear.

\section{Anti-Proliferative Therapy}

According to current guidelines [63], advanced thymic NENs remain an area of high unmet medical need with few treatment options. There are only a very small number of patients who have received anti-proliferative therapy in either neoadjuvant or salvage settings. Generally speaking, the approach has been similar to that of lung carcinoids.

As noted above, positive SRS is seen in the majority of thymic NENs. There are now several case reports showing the efficacy of somatostatin analogues, including octreotide long-acting repeatable, alone or combined with other methods [64-66]. In the phase II LUNA trial, preliminary data were presented at ESMO in 2016: in patients with either lung or thymic carcinoids, the somatostatin multireceptor ligand pasireotide caused disease stabilisation in a significant proportion of patients, but it was unclear as to the effects in the specific subgroup of 8 thymic carcinoids [67]. According to recent guidelines, somatostatin analogues have been recommended as the optimal initial treatment option, especially with SRS-positive patients, when there is residual disease post-operatively.

Regarding chemotherapy, while this is hardly discussed in most guidelines, it has nevertheless been widely used in thymic NENs. In a neoadjuvant setting, Cardillo et al. [68] reported 2 patients who had received dacarbazine, vincristine, and cyclophosphamide as induction therapy, which then rendered surgery possible, both having been excluded previously.

The results from a published phase 2 study suggest anti-tumour activity with a single agent temozolomide for

Thymic Carcinoids
Table 3. Differences between histological types in thymic NENs

\begin{tabular}{llll}
\hline Features & $\begin{array}{l}\text { Typical } \\
\text { carcinoids }\end{array}$ & $\begin{array}{l}\text { Atypical } \\
\text { carcinoids }\end{array}$ & $\begin{array}{l}\text { Neuroendocrine } \\
\text { carcinoma }\end{array}$ \\
\hline $\begin{array}{l}\text { Proportion, \% } \\
\text { 5-year recurrence } \\
\text { rate, \% }\end{array}$ & $18-36$ & $40-55$ & $19-28$ \\
$\begin{array}{l}\text { 5-year DFS, \% } \\
\text { Median OS, years }\end{array}$ & 34 & 25 & 33 \\
\hline
\end{tabular}

NENs, neuroendocrine neoplasms; DFS, disease-free survival; OS, overall survival.

well-differentiated NETs showed stable disease in 5/7 and progressive disease in $2 / 7$ patients with thymic NENs. Nevertheless, the median time to progression in the patient group as a whole was only 7 months. There was no significant difference in the time to progression between patients with broncho-pulmonary carcinoids, thymic carcinoids, or pancreatic NETs [69]. In another report [8], a partial response was seen in $2 / 10$ patients with temozolomide-based therapy and in $3 / 8$ patients with platinum-based therapy. The median time to progression was 20.5 months in patients treated with temozolomide $(n=$ 8 ) and 18 months in patients treated with platinum plus etoposide. Based on these admittedly very limited data, we might suggest temozolomide as one of the treatments to be considered for TC or AC, especially aggressive ones, and platinum-based therapy as first-line treatment for poorly differentiated tumours.

In terms of targeted therapy, tyrosine kinase inhibitors have been approved for GEP NET: sunitinib was reported as a neoadjuvant therapy in a typical thymic carcinoid combined with somatostatin analogues, showing tumour shrinkage after 3 weeks [65]. The mTOR inhibitor everolimus showed some efficacy in the subgroup of patients with lung carcinoids in the RADIANT-2 trial [70], confirmed in the RADIANT-4 trial although only one thymic carcinoid was enrolled [71]. According to the preliminary data of the recent LUNA trial, everolimus produced disease stabilisation in many patients with lung and thymic tumours, although subgroup analysis is awaited [67]. With such few cases, the role of VEGFR tyrosine kinase inhibitors and mTOR inhibitors in treating thymic NENs has not been established, but certainly suggests they merit further consideration.

Imatinib has been studied in thymic carcinomas with over-expression of mutated c-KIT gene with a V560del in exon 11, while other studies failed to detect this particular mutation. Associated with a c-KIT mutation, one case re-

Neuroendocrinology 2017;105:105-114 111 
port showed a partial response for more than 15 months [72]; in the other study with only 2 patients, the median PFS was 3 months and no partial response was recorded [73]. There is only a single case report on a good response of thymic NENs with immunohistochemical staining positive for c-KIT, although they failed to show any gene mutations in exons 9, 11, 13, and 17 [74].

Only 2 thymic NEN patients have been studied, to our knowledge, with peptide receptor radionuclide therapy with ${ }^{177} \mathrm{Lu}$-octreotate: one showed progressive disease and one stable disease at 17 months. Thus, the authors concluded that the role of treatment with ${ }^{177} \mathrm{Lu}$-octreotate in thymic carcinoids was not yet clear [75]. Nevertheless, the success of peptide radioreceptor therapy in other types of NET suggests that this should be considered as a possible therapeutic option, where available.

With all the uncertainties above, prospective studies have been advocated to define the role of chemotherapy or radiotherapy in prolonging overall survival in both adjuvant or salvage settings.

\section{Outcomes}

The median survival varies from 1.9 to 10.5 months (Table 3). Most of the suggested prognostic factors such as Ki-67, MK stage, 2015 WHO classification, and adjuvant therapy remain under debate. The only unanimous prognostic factor is the completeness of surgical resection.

\section{Conclusions}

Thymic NENs are rare tumours with highly aggressive behaviour even when TC or AC. The WHO classifications of thymic NENs are based on broncho-pulmonary carcinoids and the staging system on thymomas, despite differences. The MEN-1 syndrome is seen in some $25 \%$ of patients, and the EAS occurs frequently. Nuclear medicine techniques are helpful in identifying unexpected lesions but show no clear superiority over conventional CT scanning or MRI. Due to their malignancy, radical and prophylactic thymectomy (in MEN-1) is recommended, and aggressive treatment strategies such as radiotherapy and chemotherapy have been widely used although without any clear evidence. As for other NENs, radiolabelled ${ }^{177} \mathrm{Lu}$-octreotide is likely to be of value [76]. Finally, the diversity of tumour behaviour and lack of experience in all aspects require a multidisciplinary approach.

\section{References}

1 Gaur P, Leary C, Yao JC: Thymic neuroendocrine tumors: a SEER database analysis of 160 patients. Ann Surg 2010;251:1117-1121.

2 Shimosato Y, Mukai K: Tumors of the Mediastinum, ed 3. Washington, Armed Forces Institute of Pathology, 1995.

3 Rosai J, Levine G, Weber WR, Higa E: Carcinoid tumors and oat cell carcinomas of the thymus. Pathol Annu 1976;11:201-226.

4 Travis WD, Brambilla E, Burke AP, Marx A, Nicholson AG: WHO Classification of Tumours of the Lung, Pleura, Thymus and Heart. Lyon, IARC Press, 2015.

5 Strobel P, Zettl A, Shilo K, Chuang WY, Nicholson AG, Matsuno Y, Gal A, Laeng RH, Engel P, Capella C, Marino M, Chan JK, Rosenwald A, Travis W, Franks TJ, Ellenberger D, Schaefer IM, Marx A: Tumor genetics and survival of thymic neuroendocrine neoplasms: a multiinstitutional clinicopathologic study. Genes Chromosomes Cancer 2014;53:738-749.

6 Moran CA, Suster S: Neuroendocrine carcinomas (carcinoid tumor) of the thymus. A clinicopathologic analysis of 80 cases. Am J Clin Pathol 2000;114:100-110.

7 Filosso PL, Yao X, Ahmad U, Zhan Y, Huang J, Ruffini E, Travis W, Lucchi M, Rimner A, Antonicelli A, Guerrera F, Detterbeck F: Out- come of primary neuroendocrine tumors of the thymus: a joint analysis of the International Thymic Malignancy Interest Group and the European Society of Thoracic Surgeons databases. J Thorac Cardiovasc Surg 2015;149: 103-109.e102.

8 Crona J, Bjorklund P, Welin S, Kozlovacki G, Oberg K, Granberg D: Treatment, prognostic markers and survival in thymic neuroendocrine tumours. a study from a single tertiary referral centre. Lung Cancer 2013;79:289-293.

9 Cardillo G, Rea F, Lucchi M, Paul MA, Margaritora S, Carleo F, Marulli G, Mussi A, Granone P, Graziano P: Primary neuroendocrine tumors of the thymus: a multicenter experience of 35 patients. Ann Thorac Surg 2012;94: 241-245; discussion 245-246.

10 Ahn S, Lee JJ, Ha SY, Sung CO, Kim J, Han J: Clinicopathological analysis of 21 thymic neuroendocrine tumors. Korean J Pathol 2012;46:221-225

11 Fazio N, Milione M: Heterogeneity of grade 3 gastroenteropancreatic neuroendocrine carcinomas: new insights and treatment implications. Cancer Treat Rev 2016;50:61-67.

12 Filosso PL, Ruffini E, Lausi PO, Lucchi M, Oliaro A, Detterbeck F: Historical perspectives: the evolution of the thymic epithelial tu- mors staging system. Lung Cancer 2014;83: 126-132.

13 Masaoka A, Monden Y, Nakahara K, Tanioka T: Follow-up study of thymomas with special reference to their clinical stages. Cancer 1981; 48:2485-2492.

14 Suster S, Moran CA: Thymic carcinoma: spectrum of differentiation and histologic types. Pathology 1998;30:111-122.

15 Detterbeck FC, Stratton K, Giroux D, Asamura H, Crowley J, Falkson C, Filosso PL, Frazier AA, Giaccone G, Huang J, Kim J, Kondo K, Lucchi M, Marino M, Marom EM, Nicholson AG, Okumura M, Ruffini E, Van Schil P: The IASLC/ITMIG Thymic Epithelial Tumors Staging Project: proposal for an evidencebased stage classification system for the forthcoming (8th) edition of the TNM classification of malignant tumors. J Thorac Oncol 2014;9:S65-S72.

16 Zhao Y, Shi J, Fan L, Yang J, Hu D, Zhao H: Evaluation of the proposed International Association for the Study of Lung Cancer (IASLC)/International Thymic Malignancies Interest Group (ITMIG) staging revisions in thymic well-differentiated neuroendocrine carcinoma patients. Eur J Cardiothorac Surg 2016;49:569-573. 
17 Garcia-Yuste M, Matilla JM, Cueto A, Paniagua JM, Ramos G, Canizares MA, Muguruza I: Typical and atypical carcinoid tumours: analysis of the experience of the Spanish Multi-centric Study of Neuroendocrine Tumours of the Lung. Eur J Cardiothorac Surg 2007;31:192-197.

18 Yao JC, Hassan M, Phan A, Dagohoy C, Leary C, Mares JE, Abdalla EK, Fleming JB, Vauthey JN, Rashid A, Evans DB: One hundred years after "carcinoid": epidemiology of and prognostic factors for neuroendocrine tumors in 35,825 cases in the United States. J Clin Oncol 2008;26:3063-3072.

19 de Laat JM, Pieterman CR, van den Broek MF, Twisk JW, Hermus AR, Dekkers OM, de Herder WW, van der Horst-Schrivers AN, Drent ML, Bisschop PH, Havekes B, Vriens MR, Valk GD: Natural course and survival of neuroendocrine tumors of thymus and lung in MEN1 patients. J Clin Endocrinol Metab 2014;99:3325-3333.

20 Ruffini E, Oliaro A, Novero D, Campisi P, Filosso PL: Neuroendocrine tumors of the thymus. Thorac Surg Clin 2011;21:13-23, v.

21 Soga J, Yakuwa Y, Osaka M: Evaluation of 342 cases of mediastinal/thymic carcinoids collected from literature: a comparative study between typical carcinoids and atypical varieties. Ann Thorac Cardiovasc Surg 1999;5: 285-292.

22 Litvak A, Pietanza MC: Bronchial and thymic carcinoid tumors. Hematol Oncol Clin North Am 2016;30:83-102.

23 Wick MR, Scott RE, Li CY, Carney JA: Carcinoid tumor of the thymus: a clinicopathologic report of seven cases with a review of the literature. Mayo Clin Proc 1980;55:246-254.

24 Wilkinson S, Teh BT, Davey KR, McArdle JP, Young M, Shepherd JJ: Cause of death in multiple endocrine neoplasia type 1. Arch Surg 1993;128:683-690.

25 Bhosale P, Shah A, Wei W, Varadhachary G, Johnson V, Shah V, Kundra V: Carcinoid tumours: predicting the location of the primary neoplasm based on the sites of metastases. Eur Radiol 2013;23:400-407.

26 Ferolla P, Falchetti A, Filosso P, Tomassetti P, Tamburrano G, Avenia N, Daddi G, Puma F, Ribacchi R, Santeusanio F, Angeletti G, Brandi ML: Thymic neuroendocrine carcinoma (carcinoid) in multiple endocrine neoplasia type 1 syndrome: the Italian series. J Clin Endocrinol Metab 2005;90:2603-2609.

27 Gibril F, Chen YJ, Schrump DS, Vortmeyer A, Zhuang Z, Lubensky IA, Reynolds JC, Louie A, Entsuah LK, Huang K, Asgharian B, Jensen RT: Prospective study of thymic carcinoids in patients with multiple endocrine neoplasia type 1. J Clin Endocrinol Metab 2003;88: 1066-1081.

28 Shepherd JJ: The natural history of multiple endocrine neoplasia type 1 . Highly uncommon or highly unrecognized? Arch Surg 1991; 126:935-952.
29 Goudet P, Murat A, Binquet C, CardotBauters C, Costa A, Ruszniewski P, Niccoli P, Menegaux F, Chabrier G, Borson-Chazot F, Tabarin A, Bouchard P, Delemer B, Beckers A, Bonithon-Kopp C: Risk factors and causes of death in MEN1 disease. A GTE (Groupe d'Etude des Tumeurs Endocrines) cohort study among 758 patients. World J Surg 2010; 34:249-255.

30 Singh Ospina N, Thompson GB, C Nichols F 3rd, Cassivi SD, Young WF Jr: Thymic and bronchial carcinoid tumors in multiple endocrine neoplasia type 1: The Mayo Clinic Experience from 1977 to 2013. Horm Cancer 2015; 6:247-253.

31 Brandi ML, Gagel RF, Angeli A, Bilezikian JP, Beck-Peccoz P, Bordi C, Conte-Devolx B, Falchetti A, Gheri RG, Libroia A, Lips CJ, Lombardi G, Mannelli M, Pacini F, Ponder BA, Raue F, Skogseid B, Tamburrano G, Thakker RV, Thompson NW, Tomassetti P, Tonelli F, Wells SA Jr, Marx SJ: Guidelines for diagnosis and therapy of MEN type 1 and type 2. J Clin Endocrinol Metab 2001;86:5658-5671.

32 Otake Y, Aoki M, Nakanishi T, Hashimoto K: Atypical carcinoid of thymus associated with multiple endocrine neoplasia syndrome type 1. Gen Thorac Cardiovasc Surg 2010;58:534537.

33 Lim LC, Tan MH, Eng C, Teh BT, Rajasoorya RC: Thymic carcinoid in multiple endocrine neoplasia 1: genotype-phenotype correlation and prevention. J Intern Med 2006;259:428432.

34 Christakis I, Qiu W, Silva Figueroa AM, Hyde S, Cote GJ, Busaidy NL, Williams M, Grubbs E, Lee JE, Perrier ND: Clinical features, treatments, and outcomes of patients with thymic carcinoids and multiple endocrine neoplasia type 1 syndrome at MD Anderson Cancer Center. Horm Cancer 2016;7:279-287.

35 Sakurai A, Imai T, Kikumori T, Horiuchi K, Okamoto T, Uchino S, Kosugi S, Suzuki S, Suyama K, Yamazaki M, Sato A: Thymic neuroendocrine tumour in multiple endocrine neoplasia type 1: female patients are not rare exceptions. Clin Endocrinol (Oxf) 2013;78: 248-254.

36 Meinardi JR, Wolffenbuttel BH, Dullaart RP: Cyclic Cushing's syndrome: a clinical challenge. Eur J Endocrinol 2007;157:245-254.

37 Alexandraki KI, Grossman AB: The ectopic ACTH syndrome. Rev Endocr Metab Disord 2010;11:117-126.

38 Neary NM, Lopez-Chavez A, Abel BS, Boyce AM, Schaub N, Kwong K, Stratakis CA, Moran CA, Giaccone G, Nieman LK: Neuroendocrine ACTH-producing tumor of the thymus - experience with 12 patients over 25 years. J Clin Endocrinol Metab 2012;97:22232230.

39 Trott MJ, Farah G, Stokes VJ, Wang LM, Grossman AB: A thymic neuroendocrine tumour in a young female: a rare cause of relapsing and remitting Cushing's syndrome. Endocrinol Diabetes Metab Case Rep 2016;2016: 160018.
40 Chen YY, Li SQ, Liu HS, Qin YZ, Li L, Huang C, Bi YL, Meng YX, He J, Zhou XY, Ma DJ: Ectopic adrenocorticotropic hormone syndrome caused by neuroendocrine tumors of the thymus: 30-year experience with 16 patients at a single institute in the People's Republic of China. Onco Targets Ther 2016;9: 2193-2201.

41 Liu RX, Wang WQ, Ye L, Bi YF, Fang H, Cui B, Zhou WW, Dai M, Zhang J, Li XY, Ning G: p21-activated kinase 3 is overexpressed in thymic neuroendocrine tumors (carcinoids) with ectopic ACTH syndrome and participates in cell migration. Endocrine 2010;38: 38-47.

42 Yano M, Fukai I, Kobayashi Y, Mizuno K, Konishi A, Haneda H, Suzuki E, Endo K, Fujii Y: ACTH-secreting thymic carcinoid associated with multiple endocrine neoplasia type 1 . Ann Thorac Surg 2006;81:366-368.

43 Ghazi AA, Dezfooli AA, Mohamadi F, Yousefi SV, Amirbaigloo A, Ghazi S, Pourafkari M, Berney D, Ellard S, Grossman AB: Cushing syndrome secondary to a thymic carcinoid tumor due to multiple endocrine neoplasia type 1. Endocr Pract 2011;17:e92-e96.

44 Li X, Su J, Zhao L, Wu J, Ding X, Fang F, Wu Y, Sun H, Peng Y: Familial Cushing syndrome due to thymic carcinoids in a multiple endocrine neoplasia type 1 kindred. Endocrine 2014;47:183-190.

45 Somasundaram NP, Garusinghe C, Berney D, Grossman $\mathrm{AB}$ : A thymic carcinoid tumour causing Zollinger-Ellison and Cushing's syndromes due to ectopic ACTH and gastrin secretion. Hormones (Athens) 2013;12:305-308.

46 Pacak K, Ilias I, Chen CC, Carrasquillo JA, Whatley M, Nieman LK: The role of [(18)F] fluorodeoxyglucose positron emission tomography and [(111)In]-diethylenetriaminepentaacetate-D-Phe-pentetreotide scintigraphy in the localization of ectopic adrenocorticotropin-secreting tumors causing Cushing's syndrome. J Clin Endocrinol Metab 2004;89:2214-2221.

47 Groves AM, Mohan HK, Wegner EA, Hain SF, Bingham JB, Clarke SE: Positron emission tomography with FDG to show thymic carcinoid. AJR Am J Roentgenol 2004;182:511-513.

48 Xu H, Zhang M, Zhai G, Zhang M, Ning G, Li B: The role of integrated (18)F-FDG PET/CT in identification of ectopic ACTH secretion tumors. Endocrine 2009;36:385-391.

49 Markou A, Manning P, Kaya B, Datta SN, Bomanji JB, Conway GS: [18F]fluoro-2-deoxy-D-glucose ([18F]FDG) positron emission tomography imaging of thymic carcinoid tumor presenting with recurrent Cushing's syndrome. Eur J Endocrinol 2005;152:521-525.

50 Isidori AM, Sbardella E, Zatelli MC, Boschetti M, Vitale G, Colao A, Pivonello R: Conventional and nuclear medicine imaging in ectopic Cushing's syndrome: a systematic review. J Clin Endocrinol Metab 2015;100:32313244. 
51 Morgat C, Velayoudom-Cephise FL, Schwartz P, Guyot M, Gaye D, Vimont D, Schulz J, Mazere J, Nunes ML, Smith D, Hindie E, Fernandez P, Tabarin A: Evaluation of (68)Ga-DOTA-TOC PET/CT for the detection of duodenopancreatic neuroendocrine tumors in patients with MEN1. Eur J Nucl Med Mol Imaging 2016;43:1258-1266.

52 Hubalewska-Dydejczyk A, Fross-Baron K, Mikolajczak R, Maecke HR, Huszno B, Pach D, Sowa-Staszczak A, Janota B, Szybinski P, Kulig J: 99mTc-EDDA/HYNIC-octreotate scintigraphy, an efficient method for the detection and staging of carcinoid tumours: results of 3 years' experience. Eur J Nucl Med Mol Imaging 2006;33:1123-1133.

53 Ambrosini V, Nanni C, Zompatori M, Campana D, Tomassetti P, Castellucci P, Allegri V, Rubello D, Montini G, Franchi R, Fanti S: (68) Ga-DOTA-NOC PET/CT in comparison with CT for the detection of bone metastasis in patients with neuroendocrine tumours. Eur J Nucl Med Mol Imaging 2010;37:722727.

54 Teh BT, Grimmond S, Shepherd J, Larsson C, Hayward N: Multiple endocrine neoplasia type I: clinical syndrome to molecular genetics. Aust N Z J Surg 1995;65:708-713.

55 Teh BT, Zedenius J, Kytola S, Skogseid B, Trotter J, Choplin H, Twigg S, Farnebo F, Giraud S, Cameron D, Robinson B, Calender A, Larsson C, Salmela P: Thymic carcinoids in multiple endocrine neoplasia type 1 . Ann Surg 1998;228:99-105.

56 Li Y, Peng Y, Jiang X, Cheng Y, Zhou W, Su T, Xie J, Zhong X, Song D, Wu L, Fan L, Li M, Hong J, Wang W, Ning G, Cao Y: Whole exome sequencing of thymic neuroendocrine tumor with ectopic ACTH syndrome. Eur J Endocrinol 2017;176:187-194.

57 Burgess JR, Giles N, Shepherd JJ: Malignant thymic carcinoid is not prevented by transcervical thymectomy in multiple endocrine neoplasia type 1. Clin Endocrinol (Oxf) 2001; 55:689-693.

58 Sadacharan D, Reddy SV, Agrawal V, Agarwal G: Rapid development of thymic neuroendocrine carcinoma despite transcervical thymectomy in a patient with multiple endocrine neoplasia type 1 . Indian J Endocrinol Metab 2013;17:743-746.

59 Tiffet O, Nicholson AG, Ladas G, Sheppard MN, Goldstraw P: A clinicopathologic study of 12 neuroendocrine tumors arising in the thymus. Chest 2003;124:141-146.
60 Song Z, Zhang Y: Primary neuroendocrine tumors of the thymus: clinical review of 22 cases. Oncol Lett 2014;8:2125-2129.

61 Caplin ME, Baudin E, Ferolla P, Filosso P, Garcia-Yuste M, Lim E, Oberg K, Pelosi G, Perren A, Rossi RE, Travis WD: Pulmonary neuroendocrine (carcinoid) tumors: European Neuroendocrine Tumor Society expert consensus and recommendations for best practice for typical and atypical pulmonary carcinoids. Ann Oncol 2015;26:1604-1620.

62 Sugawara K, Mizumoto M, Numajiri H, Ohno T, Ohnishi K, Ishikawa H, Okumura T, Sakurai $\mathrm{H}$ : Proton beam therapy for a patient with a giant thymic carcinoid tumor and severe superior vena cava syndrome. Rare Tumors 2014;6:5177.

63 Oberg K, Hellman P, Ferolla P, Papotti M: Neuroendocrine bronchial and thymic tumors: ESMO Clinical Practice Guidelines for diagnosis, treatment and follow-up. Ann Oncol 2012;23(suppl 7):vii120-123.

64 Okabe N, Inoue T, Watanabe Y, Muto S, Hasegawa T, Ohsugi J, Higuchi M, Shio Y, Suzuki H: Two cases of thymic carcinoid treated with octreotide long-acting repeatable (in Japanese). Gan To Kagaku Ryoho 2014;41: 879-883.

65 Dham A, Truskinovsky AM, Dudek AZ: Thymic carcinoid responds to neoadjuvant therapy with sunitinib and octreotide: a case report. J Thorac Oncol 2008;3:94-97.

66 Filosso PL, Actis Dato GM, Ruffini E, Bretti S, Ozzello F, Mancuso M: Multidisciplinary treatment of advanced thymic neuroendocrine carcinoma (carcinoid): report of a successful case and review of the literature. J Thorac Cardiovasc Surg 2004;127:1215-1219.

67 Ferolla P, Brizzi MP, Meyer T, Mansoor W, Mazieres J, Cao CD, Lena H, Berruti A, Buikhuisen W, Stankovic M, Singh N, Chiodini E, Gislimberti G, Oberg K, Baudin E: Efficacy and safety of pasireotide LAR or everolimus alone, or in combination in patients with advanced carcinoids (NET) of the lung/thymus: results from the randomized, phase 2 LUNA study (abstract 416O). ESMO 2016 Congr, Copenhagen, October 2016.

68 Cardillo G, Treggiari S, Paul MA, Carleo F, De Massimi AR, Remotti D, Graziano P, Martelli M: Primary neuroendocrine tumours of the thymus: a clinicopathologic and prognostic study in 19 patients. Eur J Cardiothorac Surg 2010;37:814-818.

69 Ekeblad S, Sundin A, Janson ET, Welin S, Granberg D, Kindmark H, Dunder K, Kozlovacki $G$, Orlefors $H$, Sigurd M, Oberg K, Eriksson B, Skogseid B: Temozolomide as monotherapy is effective in treatment of advanced malignant neuroendocrine tumors. Clin Cancer Res 2007;13:2986-2991.
70 Fazio N, Granberg D, Grossman A, Saletan S, Klimovsky J, Panneerselvam A, Wolin EM: Everolimus plus octreotide long-acting repeatable in patients with advanced lung neuroendocrine tumors: analysis of the phase 3, randomized, placebo-controlled RADIANT-2 study. Chest 2013;143:955-962.

71 Yao JC, Fazio N, Singh S, Buzzoni R, Carnaghi C, Wolin E, Tomasek J, Raderer M, Lahner H, Voi M, Pacaud LB, Rouyrre N, Sachs C, Valle JW, Delle Fave G, Van Cutsem E, Tesselaar M, Shimada Y, Oh DY, Strosberg J, Kulke MH, Pavel ME: Everolimus for the treatment of advanced, non-functional neuroendocrine tumours of the lung or gastrointestinal tract (RADIANT-4): a randomised, placebo-controlled, phase 3 study. Lancet 2016;387:968977.

72 Lim SH, Lee JY, Sun JM, Kim KM, Ahn JS, Ahn MJ, Park K: A new KIT gene mutation in thymic cancer and a promising response to imatinib. J Thorac Oncol 2013;8:e91-e92.

73 Palmieri G, Marino M, Buonerba C, Federico P, Conti S, Milella M, Petillo L, Evoli A, Lalle M, Ceribelli A, Merola G, Matano E, Sioletic S, De Placido S, Di Lorenzo G, Damiano V: Imatinib mesylate in thymic epithelial malignancies. Cancer Chemother Pharmacol 2012; 69:309-315.

74 Hamada S, Masago K, Mio T, Hirota S, Mishima M: Good clinical response to imatinib mesylate in atypical thymic carcinoid with KIT overexpression. J Clin Oncol 2011;29:e9-e10.

75 van Essen M, Krenning EP, Bakker WH, de Herder WW, van Aken MO, Kwekkeboom DJ: Peptide receptor radionuclide therapy with $177 \mathrm{Lu}$-octreotate in patients with foregut carcinoid tumours of bronchial, gastric and thymic origin. Eur J Nucl Med Mol Imaging 2007;34:1219-1227.

76 Strosberg J, El-Haddad G, Wolin E, Hendifar A, Yao J, Chasen B, Mittra E, Kunz PL, Kulke MH, Jacene H, Bushnell D, O'Dorisio TM, Baum RP, Kulkarni HR, Caplin M, Lebtahi R, Hobday T, Delpassand E, Van Cutsem E, Benson A, Srirajaskanthan R, Pavel M, Mora J, Berlin J, Grande E, Reed N, Seregni E, Oberg K, Lopera Sierra M, Santoro P, Thevenet T, Erion JL, Ruszniewski P, Kwekkeboom D, Krenning E: Phase 3 trial of $177 \mathrm{Lu}$-dotatate for midgut neuroendocrine tumors. N Engl J Med 2017;376:125-135. 